\title{
ENTENDENDO O ASSÉDIO SEXUAL E A IMPORTÂNCIA DAS RELAÇÕES DE GÊNERO: INPUTS DA PESQUISA EMPÍRICA PARA O TRATAMENTO JURÍDICO-PENAL DA QUESTÃO
}

UNDERSTANDING SEXUAL HARASSMENT AND THE IMPORTANCE OF GENDER RELATIONS: INPUTS OF EMPIRICAL RESEARCH FOR THE LEGAL-PENAL TREATMENT OF THE ISSUE

\author{
Beatriz Corrêa Camargo ${ }^{1}$ \\ Universidade Federal de Uberlândia
}

\section{Resumo}

O assédio sexual constitui um fenômeno de difícil conceituação, sendo diversos os contextos em que essa expressão é utilizada. A partir de contribuições empíricas, busca-se analisar seu conceito e tipologia, desconstruindo-se mitos e estabelecendo a importância do gênero para sua percepção.

Palavras-Chaves

Assédio sexual. Gênero. Direito Penal

Abstract

Sexual harassment is a phenomenon that is difficult to conceptualize, with different contexts in which this expression is used. Based on empirical contributions, its concept and typology will be analyzed, deconstructing myths and establishing the importance of gender for its perception.

Keywords

Sexual harassment. Gender. Criminal law

${ }^{1}$ Professora de Direito Penal na Faculdade de Direito da Universidade Federal de Uberlândia. Mestre em Direito Penal pela Universidade de Bonn (Alemanha). Doutora e Pós-Doutora em Direito Penal pela Faculdade de Direito da Universidade de São Paulo. 


\section{INTRODUÇÃO}

No Brasil, a retomada no debate público sobre o assédio sexual de mulheres se intensificou a partir do ano de 2015. Como nos anos 70, quando a expressão surge pela primeira $v^{2}{ }^{2}$, o propósito almejado nesse debate é uma transformação no plano político-cultural, a ser conquistada por meio de diversos mecanismos de composição social, dentre eles o Direito.

O Direito Penal, em diversos países ${ }^{3}$, e finalmente também no Brasil ${ }^{4}$, assimilou recentemente a criação de novos delitos, como também a reforma de crimes já existentes, em resposta a essas movimentações ${ }^{5}$, que reverberaram em nível global através da rede mundial de computadores 6 .

O objetivo deste artigo se situa no âmbito da pesquisa sobre os fatos que são relevantes ao Direito, no sentido apontado por Urs

2 Referências sobre a origem do termo são encontradas em SIEGEL, 2004, p. 8; BAKER, 2008, p.1; SAGUY, 2003, p. 178. Uma discussão pormenorizada a respeito é desenvolvida em CAMARGO, 2019 (no prelo).

${ }^{3}$ Mencionem-se, a título de exemplo, as reformas para a punição pela prática do assédio sexual na França, nos anos de 2012 e 2017 (Artigos 222-33 e 225-2 do Código Penal francês), na Áustria em 2017 (§ 218 do Código Penal austríaco), e na Alemanha (§ 184i do Código Penal alemão) no ano de 2017. Acerca da reforma alemã cf. CAMARGO, 2017, p. 16-17.

${ }^{4}$ Com a criação do art. 215-A, CP, no ano de 2018.

${ }^{5}$ Sobre os movimentos para proteção contra o assédio sexual, a discriminação e a violência de gênero nas universidades brasileiras, veja CAMARGO, 2016, p. 61-73. ${ }^{6}$ Nesse sentido, podem-se mencionar campanhas como a \#PrimeiroAssedio ou a \#MeToo. A respeito, vide ainda CAMARGO; SILVEIRA, 2018, p. 10-11. 
Kindhäuser acerca das possíveis tarefas a serem desempenhadas pela dogmática penal ${ }^{7}$. Mais concretamente, objetiva-se apresentar alguns dos aportes mais recentes sobre a dinâmica do assédio sexual, desde a perspectiva de estudos em psicologia social, com base em pesquisas quantitativas e qualitativas, a fim de compreender melhor esse fenômeno.

Para o Direito Penal, essa investigação é de interesse por diversas razões. Primeiramente, importa conhecer a prevalência desse tipo de comportamento na sociedade, em variados contextos, mensurando-se, deste modo, a sua importância enquanto problema que mereça a atenção de uma política pública no âmbito criminal, que pode ser concretizada, por exemplo, através da criação de novos tipos penais.

Além disso, um estudo dessa natureza oferece subsídio para a necessidade, existente, de uma definição jurídica satisfatória do assédio sexual. Frequentemente, falta clareza na literatura científica e no debate público acerca do que se refere exatamente o assédio sexual. Por limitações de espaço, não iremos aprofundar aqui o problema conceitual a que nos referimos. Contudo, pretendemos apresentar brevemente o modo como as pesquisas de referência lidam com a conceituação do assédio, a fim de elucidar as dinâmicas de interação entre os sujeitos envolvidos.

Por fim, o que esse mergulho no mundo das pesquisas empíricas sobre o assédio sexual permite demonstrar é que se trata de um fenômeno intrinsecamente ligado às relações e aos papéis de

${ }^{7}$ KINDHÄUSER, 2009, p. 955. 
gênero, que aqui serão analisados desde a ótica peculiar da psicologia social. A convergência dos estudos apresentados deve servir de respaldo ao convencimento de que nossos preconceitos e demais mecanismos psicológicos de autopreservação, em matéria de sexualidade e afirmação social, sempre direcionados à busca de pertencimento ao grupo, impedem muitas vezes a própria identificação acerca dos conflitos colocados, dificultam uma interpretação equilibrada sobre os componentes de tais conflitos, e, por consequência, nos distanciam de soluções que garantam a vigência dos direitos injustamente afetados.

Levantarei, assim, algumas das questões que são investigadas acerca do assédio sexual cujo esclarecimento me parece importante para o jurista nas mais diversas frentes de trabalho. Essa escolha foi orientada pelo ensejo de apresentar uma compreensão introdutória acerca do tema. Outras tantas questões igualmente importantes para o Direito não puderam ser contempladas por razões de espaço. Gostaria de mencionar, como exemplo, a pergunta sobre a porcentagem de vítimas que denunciam os abusos sofridos, os danos causados pelo assédio sexual, informações sobre a relação de hierarquia existente entre o assediador e a vítima, ou, ainda, a discussão sobre as possíveis medidas institucionais que podem ser desenvolvidas a fim de prevenirem a prática do assédio a partir de diversas variáveis, dentre elas os estudos sobre os traços de personalidade dos assediadores. Há questões que ainda carecem de investigação empírica para dados mais concretos, como a intersecção entre o gênero e a etnia. Embora concebido como um guia ao pesquisador e ao operador do direito, esse estudo oferece uma revisão da literatura científica que também pode 
ser útil aos pesquisadores e profissionais de outras áreas das ciências sociais.

\section{2. "O" assédio sexual: contextos de uso da expressão}

Em linhas muito gerais, pode-se dizer que o assédio consiste em um comportamento de natureza ou conotação sexual, indesejado ou não consentido pela pessoa a quem é dirigido. Entretanto, saindo dessa generalidade, a formulação de um conceito concreto capaz de dar conta de todas as instâncias daquilo que se designa como "assédio sexual" se mostra tarefa bastante espinhosa.

Conforme se mencionou há pouco, a expressão é relativamente recente. Ela surgiu no contexto da segunda onda feminista com o propósito de reivindicar maior respeito à igualdade de homens e mulheres, particularmente no campo do trabalho ${ }^{8}$. Naquele momento, o objeto da discussão não era o problema da autonomia sexual, e sim a questão da igualdade de oportunidades no que se refere à emancipação econômica e o reconhecimento social da capacidade profissional das mulheres.

Posteriormente, essa expressão foi apropriada em outros contextos, sendo possível dizer que pelo menos no Brasil a discussão atual sobre o assédio sexual acentua o assédio como um conflito localizado no campo da sexualidade, relativamente à liberdade sexual das mulheres. Saiu-se das instituições para o espaço público, contexto esse que no debate feminista foi apelidado de "assédio sexual de rua" ("street

${ }^{8}$ Paradigmático, MACKINNON, 1979. 
harassment') $)^{9}$. Muito mais do que uma preocupação com a igualdade de oportunidades, ou com a discriminação de gênero, o foco agora é dado no direito de dispor do próprio corpo.

Assim, tanto linguística como pragmaticamente, é duvidosa qualquer tentativa de oferecer uma definição completa e coesa, já que são muito variadas as ocasiões nas quais essa expressão é utilizada ${ }^{10}$. Notar essa dificuldade é importante para o trabalho do jurista, já que o caráter difuso das situações envolvidas no assédio oferece um desafio particular às necessidades de formulação legislativa para coibir a prática do assédio sexual ${ }^{11}$.

Apenas a título de exemplo, podemos considerar a variedade de maneiras que uma pessoa pode ser sexualmente assediada: isso pode envolver o toque no corpo dela, ser apenas verbal ou mesmo visual através de imagens ou gestos. Da mesma forma, é possível que a pessoa assediada sexualmente não consinta com a ação do assediador simplesmente porque foi pega de surpresa, ou então que ela se cale com algo que não concorda pelo medo de sofrer uma agressão ou retaliação, etc. Ao mesmo tempo, muitas atitudes podem ser facilmente identificadas como abusivas para um observador, sem que isso esteja tão claro para a pessoa que está diretamente envolvida na situação.

${ }^{9}$ Sobre as dificuldades de utilização dessa expressão na análise científica, veja-se a discussão em VERA-GRAY, 2016, p. 11.

${ }^{10}$ Lembro aqui da metáfora de Ludwig Wittgenstein sobre a relação de uma linha em relação aos fios que a transpassam (WITTGENSTEIN, 2006, § 67).

${ }^{11}$ Sobre essa questão, CAMARGO, 2019 (no prelo); CAMARGO; SILVEIRA, 2018, p. 11. 
Justamente por essa variação é que as pesquisas empíricas nessa área partem antes de uma estruturação das dinâmicas envolvidas e buscam medir a prevalência dessas condutas a partir de uma diferenciação sobre o modo de abordagem presente no assédio sexual ${ }^{12}$. Ademais, é importante lembrar que questionários e entrevistas raramente se limitam a formular perguntas genéricas do tipo "você já sofreu assédio sexual", na medida em que se deixa uma margem muito subjetiva de interpretação para os entrevistados. Geralmente, apresenta-se um rol de situações que os próprios pesquisadores consideram ser casos de assédio. Isso também deve ser tido em conta na mensuração dessas pesquisas pelo jurista.

\section{Tipologia do assédio sexual}

Grande parte das pesquisas e da literatura científica sobre o assédio sexual toma por referência o estudo feito por Michele Gelfand, Louise Fitzgerald e Fritz Drasgow ainda nos anos 90, quando se diferenciaram três formas de interação no que se refere ao assédio sexual ${ }^{13}$. Essa distinção analítica foi testada em contextos institucionais variados em países diversos, inclusive em culturas que até então desconheciam a discussão sobre o assédio sexual, isto é, as quais sequer tinham um nome para o fenômeno ${ }^{14}$.

${ }^{12}$ Com maiores detalhes, veja-se o item 3 abaixo.

13 Sobre outras tipologias sugeridas na literatura científica, bem como sobre a sustentação dessas propostas, vide a discussão desenvolvida por VANSELOW, 2009, p. 6-12.

${ }^{14}$ GELFAND; FITZGERALD; DRASGOW, 1995, p. 164-177. 
Basicamente, o que esses autores propõem é uma tripartição do conceito de assédio sexual. O primeiro consiste na atenção sexual indesejada pela pessoa que é objeto dessas atenções ("unwanted sexual attention"), usualmente quando a atitude visa algum tipo de cooperação sexual da pessoa. Tais casos englobam desde comentários de cunho sexual sobre a aparência física da pessoa assediada, olhares ostensivos sobre as partes íntimas, pressão para encontros, toques indesejados, até o extremo de uma violência sexual. Outra dinâmica se estabelece quando se trata de uma coerção de natureza sexual ("sexual coercion") direcionada contra a vítima, já que aqui entram em cena situações de chantagem e o recurso a ameaças ao seu bem-estar no caso de uma recusa. Por fim, distingue-se o assédio de gênero ("gender harassment"), que é aquele praticado por meio de atitudes insultantes e degradantes em razão do gênero ou mesmo da orientação sexual, como piadas de cunho sexual ou envio de material pornográfico fora de contexto. Um exemplo interessante nesse sentido foi o caso mencionado por Catharine MacKinnon a respeito de uma fábrica de sabão, onde a única mulher que trabalhava na firma sempre encontrava um sabão cortado em formato de pênis, enviado regularmente para sua esteira de serviço. ${ }^{15}$

Essa diferenciação serve de base para uma série de perguntas, importantes também para o tratamento jurídico do assédio sexual. Assim, é possível perceber que condutas tidas como mais graves como

${ }^{15}$ MACKINNON, 1993, p. 47. 
a coerção sexual ${ }^{16}$ não são necessariamente as mais frequentes ${ }^{17}$. Além disso, cada uma dessas formas de agressão dá margens à interpretação sobre as diversas motivações que se escondem por trás delas, como veremos melhor adiante ${ }^{18}$.

\section{Prevalência de homens como agressores e mulheres como vítimas}

Diversos estudos medem a porcentagem de mulheres que já foram vítimas de assédio sexual, em contextos diversos. No Brasil, duas pesquisas foram notabilizadas, com números que se encontram na média indicada por pesquisas realizadas em outros países. Uma pesquisa do Datafolha do ano de 2017 mediu a incidência do assédio sexual, verbal e físico, entre mulheres com 16 anos ou mais no país. Ao todo, $42 \%$ das entrevistadas relataram já ter sofrido uma situação de assédio sexual, seja na rua, no transporte público, em casa, no trabalho ou nas instituições de ensino ${ }^{19}$. No ambiente universitário brasileiro, a

${ }^{16}$ Punida nos artigos 213 e 216-A do CP.

${ }^{17}$ A respeito, GELFAND; FITZGERALD; DRASGOW, 1995, p. 168; DIEHL; REES; BOHNER, 2012, p. 522. Apenas para oferecer um exemplo, o estudo de Morral, Gore e Schell indicam a porcentagem de $1,66 \%$ de mulheres e $0,35 \%$ de homens que sofreram com esse tipo de assédio nas forças armadas estadunidenses no ano de 2014. Cf. MORRAL et al., 2015, p. 33.

18 Veja o item 5 abaixo.

${ }^{19}$ Nas ruas, uma em cada três brasileiras adultas (29\%) declarou já ter sofrido assédio sexual, sendo que $25 \%$ que sofreram assédio verbal, e $3 \%$, físico, além dos que sofreram ambos. $\mathrm{O}$ assédio em transporte público foi relatado por $22 \%$, com incidência similar entre assédio físico (11\%) e verbal (8\%). O assédio no trabalho foi relatado por $15 \%$ das brasileiras, incluindo as formas de assédio físico (2\%) e verbal (11\%). Há ainda $10 \%$ que já foram assediadas sexualmente na escola ou faculdade 
vitimização das mulheres quanto ao assédio sexual foi medida por uma pesquisa do Data Popular em parceria com o Instituto Avon. A pesquisa revelou que $56 \%$ já sofreram comentários com apelos sexuais indesejados, cantadas ofensivas ou uma abordagem agressiva nesse contexto $^{20}$.

Na medida em que grande parte das pesquisas tenham como propósito saber a dimensão do assédio sexual como problema social, é natural que sigam a percepção intuitiva, confirmada pelos dados empíricos, de que são as mulheres o principal grupo afetado por essas práticas. Por isso, há poucos estudos que se debruçam particularmente sobre o problema dos homens como vítimas do assédio sexual, o que igualmente se deve ao fato de que em culturas fortemente machistas, os homens encontrem dificuldades para reconhecer e abordar essa temática.

Comecemos pelos números. Primeiramente, é importante observar que são particularmente as pesquisas desenvolvidas no ambiente institucional aquelas que mensuram o número de homens afetados pelo assédio sexual. A despeito da variação das pesquisas que medem o índice de assédio sexual sofrido por mulheres e homens, existe uma média estimativa no sentido de que aproximadamente $50 \%$ das mulheres e pelo menos $10 \%$ dos homens tenham sidos assediados sexualmente durante a sua vida de trabalho ${ }^{21}$.

( $8 \%$ verbalmente, e $1 \%$ fisicamente) e $6 \%$ que já sofreram assédio dentro de casa ( $1 \%$ verbalmente, e 4\% fisicamente). Cf. pesquisa detalhada: DATAFOLHA, 2017.

${ }^{20}$ DATA POPULAR; INSTITUTO AVON, 2015.

${ }^{21}$ VANSELOW, 2009, p. 14. 
Um importante estudo representativo nesse sentido iniciou-se nos Estados Unidos, ainda na década de 1980, com o propósito de medir a incidência do assédio sexual contra funcionários homens e mulheres do governo federal estadunidense. Na última amostragem, de 1994, tem-se números semelhantes aos anos anteriores, com uma proporção de $44 \%$ das mulheres atingidas, em comparação com 19\% de homens que já haviam sofrido alguma forma de assédio sexual no serviço federal $^{22}$. É um número relativamente alto no que se refere à vitimização masculina, quando comparado com outros estudos. Ainda nos Estados Unidos, a avaliação mais recente de uma pesquisa periódica, que se realiza há décadas, indica que apenas no ano de 2014, cerca de $22 \%$ das mulheres que trabalham nas forças armadas americanas haviam sofrido diferentes formas de assédio sexual, ao passo que em relação aos homens esse número foi de $7 \%{ }^{23}$. Um levantamento da União Europeia de 1998 oferece proporções similares no contexto laboral da Inglaterra: $54 \%$ das mulheres, em comparação a $9 \%$ homens, já haviam passado por situações de assédio sexual alguma vez na vida ${ }^{24}$. No Brasil, uma pesquisa que mediu casos de assédio moral e sexual no âmbito das guardas municipais brasileiras constatou que $33,6 \%$ das mulheres já se sentiram discriminadas, humilhadas, desrespeitadas, constrangidas ou assediadas por questões

${ }^{22}$ US MERIT SYSTEMS PROTECTION BOARD, 1995, p. vii.

${ }^{23}$ MORRAL et al., 2015, p. 31 e ss.

${ }^{24}$ EUROPEAN COMMISSION, 1998, p. 133. 
de gênero ou orientação afetivo-sexual. Em contrapartida, apenas 4,4\% dos homens relataram o mesmo problema ${ }^{25}$.

Para além da expressiva diferença numérica na vitimização das mulheres em comparação com a vitimização dos homens, é importante observar que o fator de gênero ainda se reflete na composição do grupo de agressores, auxiliando também a compreender as diferenças em relação ao assédio sofrido por pessoas do sexo masculino. Nesse sentido, estudos indicam que ao menos em 1/3 dos casos o assédio sexual sofrido pelos homens é praticado por outros homens ${ }^{26}$, ao passo que raramente o assédio sexual sofrido por uma mulher foi praticado por outra mulher ${ }^{27}$. Ou seja: praticamente todas as mulheres são

${ }^{25}$ CARDEAL; RIBEIRO, 2017, p. 65.

${ }^{26}$ Há estudos que apresentam números mais altos para o assédio praticado por homens contra homens. Essa média foi feita por VANSELOW, 2009, p. 16. O estudo de RUSSELL; OSWALD, 2016, p. 525, indica pesquisas que mediram entre $40 \%$ e $52 \%$ de prevalência de homens como assediadores sexuais de outros homens. Anteriormente, WALDO; BERDAHL; FITZGERALD, 1998, p. 62, 69, 73, haviam indicado pesquisas que apresentaram números entre $21 \%$ e $37 \%$ de homens assediando outros homens.

${ }^{27}$ A pesquisa de WALDO; BERDAHL; FITZGERALD, 1998, p. 62, apresenta baixos índices de assédio de mulheres praticados contra outras mulheres, ficando entre $1 \%$ e $3 \%$ dos casos. VANSELOW, 2009, p. 16, indica igualmente um estudo feito na Alemanha com o mesmo índice: $97 \%$ das mulheres assediadas por homens. Conforme o levantamento mais recente feito em 2014 pelo Departament of Defense nos EUA, 75\% dos assédios sexuais foram praticados exclusivamente por homens (sozinhos ou em grupo), ao passo que apenas $11 \%$ foi praticado exclusivamente por mulheres. Mediu-se também a prática do assédio por grupos compostos por homens e mulheres, o que ficou em 14\% dos casos. Cf. MORRAL, 2015, p. 33. 
assediadas por homens, sendo os homens também responsáveis pelo assédio sexual de outros homens em grande parte das vezes.

De acordo com os pesquisadores, essa discrepância pode ser explicada quando se tem em vista que o assédio sexual não é uma conduta motivada apenas por interesses sexuais. Esse tipo de comportamento reflete, igualmente, um modo de reação aos indivíduos, de ambos os sexos, que não se comportam conforme os papéis de gênero atribuídos a eles. Estudos indicam, nesse sentido, que é maior a probabilidade de vitimização pelo assédio sexual para lésbicas, homossexuais e pessoas que fogem do estereótipo feminino ou masculino ${ }^{28}$. Assim, o assédio sexual está presente nos modos cotidianos de interação masculina, mesmo em casos mais banais de estudantes que enviam material pornográfico ao colega, sem a sua aceitação prévia ou aderência. A depender do contexto, isso pode significar uma maneira de impor o padrão de masculinidade seguido pelo grupo ao indivíduo em questão. Uma lesão ao seu direito de autodeterminação sexual em diversos níveis, portanto.

\section{Por que tantos homens assediam as mulheres, afinal?}

Um recente estudo propôs a investigação sobre a motivação por trás do assédio sexual ${ }^{29}$, a partir das três categorias de assédio sexual que indicamos há pouco ${ }^{30}$.

28 VANSELOW, 2009, p. 20.

${ }^{29}$ Trata-se da pesquisa desenvolvida por DIEHL; REES; BOHNER, 2012, p. 521-531.

${ }^{30}$ A respeito, vide o item 3 acima. 
No estudo, Charlotte Diehl, Jonas Rees e Gerd Bohner apresentam uma revisão da literatura sobre as evidências empíricas acerca da explicação do assédio sexual. Quanto às premissas, a comunidade científica se divide entre uma explicação de cunho evolucionista e uma explicação de base sociocultural para o problema - uma discussão desde sempre presente no estudo da sexualidade pelas chamadas "ciências sexuais"31.

De acordo com a explicação evolucionista, o assédio sexual pode ser entendido como uma situação de desentendimento entre os gêneros, devido a um conflito de estratégias de copulação empregadas por machos e fêmeas. Biologicamente, estariam os homens condicionados a estratégias de curto prazo, ao passo que as mulheres seriam tipicamente dirigidas por estratégias de longo prazo a fim de encontrar seus parceiros. Nesse sentido, os gêneros traduzem estratégias distintas em razão das distintas funções desempenhadas por cada qual no propósito de perpetuação da espécie.

Já a explicação sociocultural procura contextualizar o assédio sexual como expressão da dinâmica de poderes estabelecida entre os gêneros. Desde essa perspectiva, o fenômeno pode ser compreendido como estratégia (inconsciente) de manutenção de poder no sistema patriarcal através da opressão das mulheres dentro do grupo em que se inserem. Desta forma, o assédio sexual seria uma forma de intimidar as mulheres que abandonam seus papéis tradicionais e passam a competir com os homens em áreas tradicionalmente dominadas por eles.

${ }^{31}$ A respeito, WREDE, 2000, p. 40; SIGUSCH, 2011, p. 42 e ss. 
Cada uma dessas teorias possui respaldo em evidências empíricas, que no geral são bastante escassas. Sobre a explicação evolucionista, há pesquisas que concluem sobre o fato de que existe uma diferença de percepção por cada um dos gêneros sobre o contexto dado. Nesse sentido, as mulheres costumam identificar melhor casos de assédio sexual do que os homens, assim como a julgar tais situações com maior severidade do que os homens. Da mesma forma, os homens parecem não perceber adequadamente o real interesse sexual de uma mulher, especialmente quando estão orientados fortemente a um contato sexual a curto prazo e quando a mulher é bastante atraente. ${ }^{32}$

Em contrapartida, há importantes evidências em favor da tese sociocultural. Alguns estudos demostram que, em situações de confrontação, os homens instrumentalizam o assédio sexual para punir a falta de conformidade ao papel sexual das mulheres ou para reafirmar uma identidade masculina forte. Isso foi evidenciado através da maior incidência do assédio em situações nas quais o alvo expressou atitudes igualitárias sobre o papel de gênero, também quando se tratava de um ambiente com polarização de grupos masculinos vs. femininos, e ainda nos casos em que a identidade de gênero do participante havia sido ameaçada via feedback. ${ }^{33}$

A hipótese de Diehl, Rees e Bohner no estudo que conduziram é a de que cada uma dessas explicações oferece suporte para compreender as possíveis motivações por trás do assédio sexual, correlacionando-as com o tipo de assédio praticado. Particularmente,

${ }^{32}$ DIEHL; REES; BOHNER, 2012, p. 523.

33 Maiores detalhes em DIEHL; REES; BOHNER, 2012, p. 523. 
foi comparada a prática do assédio sexual de gênero por meio de brincadeiras sexistas com o assédio que consiste em atenção sexual indesejada, no caso, representado por comentários de conteúdo sexual sobre a mulher a quem os homens se dirigiam. A conclusão do estudo é a de que o assédio sexual de gênero expressa sempre um sexismo hostil do assediador para com o seu alvo, ao passo que a atenção sexual indesejada pode servir tanto como meio de estabelecer uma hostilidade sexista quanto expressar um interesse sexual por parte do assediador.

Aqui, os pesquisadores chamam a atenção para a importância de compreender essas dinâmicas não apenas a fim de estabelecer estratégias eficazes de esclarecimento e prevenção do assédio sexual, como ainda para interpretar um segundo fenômeno relacionado ao assédio sexual, que é a utilização de estratégias de justificação e exoneração de responsabilidade dos assediadores, os chamados "mitos sobre o assédio sexual". Assim, os autores sugerem que quando o assédio sexual for orientado pelo sexismo hostil, a tendência de justificação do comportamento através desses mitos será muito mais provável. Em casos orientados pelo interesse sexual do assediador, será mais fácil para ele neutralizar o assédio enquadrandoo como parte de um flirt malsucedido ${ }^{34}$.

\section{Os mitos sobre o assédio sexual}

Outro fator relevante a ser considerado na questão sobre o assédio sexual é a observação dos padrões psicológicos de justificação para comportamentos assediadores. São estratégias semelhantes ao que

${ }^{34}$ DIEHL; REES; BOHNER, 2012, p. 524. 
se observa quanto aos chamados "mitos sobre a agressão sexual". Embora inverídicas, são crenças persistentes e duradouras sobre a maneira como ocorrem as agressões sexuais, bem como os seus efeitos e as suas causas.

Vale notar que necessidade psicológica de justificação para o assediador ou minimização dos efeitos nocivos do assédio apenas surge quando existe uma mudança de percepção social sobre a adequação desta conduta no conjunto de valores vigentes ${ }^{35}$.

Apesar de certa variação na literatura científica no que se refere à constituição dos mitos sobre o abuso sexual, Gerd Bohner et al. identificam um consenso acerca de quatro formas típicas pelas quais esses mitos se expressam, quais sejam: (i) culpar a vítima pela agressão sofrida; (ii) expressar descrença sobre as acusações de agressão sexual; (iii) exonerar o agressor de responsabilidade por motivos variados; (iv) afirmar que apenas alguns tipos de mulheres sofrem agressões dessa natureza ${ }^{36}$.

Assim, são frequentes generalizações no sentido de que o assédio sexual é próprio da natureza masculina, que esses incidentes frequentemente não passam de encenação das mulheres que os denunciam, ou, ainda, que uma pessoa pode simplesmente dizer "não" para as condutas que não deseja ou com as quais não concorda ${ }^{37}$.

Quando utilizados como chave de leitura pelo julgador, os mitos sobre o assédio sexual afetam uma análise ponderada sobre o caso

${ }^{35}$ DIEHL; REES; BOHNER, 2012, p. 524.

${ }^{36}$ BOHNER et al., 2009, p. 17-45.

${ }^{37}$ A respeito, DIEHL; REES; BOHNER, 2014, p. 27. 
concreto. Sua função, como já se adiantou, é justificar o assediador ou neutralizar a importância do assédio sexual. A esses mitos se agarram tanto homens quanto mulheres, diante da necessidade de racionalização do acontecimento. Os homens o fazem com o propósito da auto-justificação (de si próprios, individualmente, ou do grupo ao qual pertencem), sendo importante ressaltar que esse movimento pode ser consciente ou inconsciente. Por sua vez, muitas mulheres racionalizam os episódios de assédio sexual através dos mitos como meio de garantir a ilusão da própria segurança, como se o pertencimento a uma "classe" distinta de mulheres fosse capaz de torná-las imunes a esse tipo de constrangimento. ${ }^{38}$

7. Por que ela simplesmente não se opôs?

Do mesmo modo que os mitos sobre o assédio sexual oferecem uma chave de leitura equivocada para as pessoas responsáveis pela resolução institucional de um caso posto, é de fundamental importância o entendimento sobre as possibilidades de reação da vítima do assédio sexual diante das agressões por ela sofridas.

Nesse sentido, o que alguns pesquisadores discutem é que existe muitas vezes uma sobrevalorização da capacidade das pessoas de se afastarem de situações com as quais não se sentem confortáveis ou que lhes afetam negativamente. Em realidade, há diversas razões pelas quais uma pessoa, particularmente as mulheres, não se opõem ou não denunciam às autoridades quando sofrem com o assédio sexual.

${ }^{38}$ DIEHL; GLASER; BOHNER, 2014, p. 490. 
Dentre essas razões, há diversos receios, justificados em maior ou menor medida, tais como o medo de não ser acreditada, de ser afetada negativamente na carreira caso um conflito venha a eclodir, bem como o temor de se sentir envergonhada e humilhada em situações de auto-exposição. Algumas percepções também favorecem a passividade diante do assédio sexual sofrido, como, por exemplo, a crença de que não se tem o direito de "destruir a vida do outro" com uma denúncia, ou a convicção de que nada pode ser feito a respeito. Por fim, não raro se percebe o recurso a estratégias psíquicas internas (“coping") que negam a dimensão do ocorrido para lidar com o peso emocional que ele representa ${ }^{39}$.

Diante desse quadro, não é incomum que a inércia da vítima seja interpretada em seu desfavor, ao invés de ser compreendida como reação possível dentro de um estado de intenso sofrimento psíquico, ou, mesmo, de simples resignação diante da ausência de condições adequadas para reivindicar seus direitos de forma segura.

Em um de seus estudos, Louise Fitzgerald, Suzanne Swan e Karla Fischer analisam dois esquemas argumentativos frequentemente utilizados nas cortes americanas, nos quais a ausência de uma reação enfática ou imediata da vítima (no caso, das mulheres) é apresentada como hipótese de consentimentos com o assédio. ${ }^{40}$

O primeiro deles representa a pessoa que sofre o assédio na figura de "uma tolerante silenciosa" ("the silent tolerator"). Aqui, a

\footnotetext{
${ }^{39}$ A respeito, FITZGERALD; SWAN; FISCHER, 1995, p. 118 e ss., p. 123 e s., p. 126 e s.; HOLZBECHER; BRASZEIT; MÜLLER; PLOGSTEDT, 1997, p. 66, 68.

${ }^{40}$ FITZGERALD; SWAN; FISCHER, 1995, p. 131 e ss.
} 
conduta do assediador é vista como secretamente desejada pela vítima, já que a mesma não se opôs explicitamente ao assédio, ficando, antes disso, em silêncio. Foi o caso do julgamento em desfavor da estudante que silenciou com relação às investidas frequentes do seu chefe no governo do Estado de Minnesota (Kresko v. Rulli, 1988). Enquanto simples estagiária, a vítima não via meios de se opor diretamente à aproximação, de fato indesejada para ela, de seu superior, já que qualquer movimento poderia significar a perda do emprego. Assim, a única alternativa que encontrou foi o retraimento e o esquivo em relação às investidas do chefe. Outro exemplo foi o caso da escrevente que estava sentada ao lado do juiz durante uma sessão no Tribunal (U.S. v. Lanier, 1992). Por baixo da mesa, o juiz colocou as mãos entre as pernas da funcionária, em suas genitais. $\mathrm{Na}$ hora, ela silenciou evitando tumulto durante a audiência. Ainda que tivesse reclamado sobre o ocorrido para as autoridades competentes logo em seguida, esse silêncio foi considerado como uma falha em expressar de modo suficientemente claro que ela não desejava esse tipo de atitude.

$\mathrm{O}$ segundo quadro interpretativo indicado pelas pesquisadoras é a situação da vítima que é apresentada como se fosse uma instigadora do assédio sexual ("the instigator-in-kind"). Assim, a vítima é vista como alguém que coopera com a conduta, quando, em verdade, sua reação reflete uma tentativa de apaziguamento e de sobrevivência no ambiente em que se encontra. Esse foi o caso Reed, uma policial nos EUA (Reed $v$. Shephard, 1991). Reed era assediada pelos colegas com quem trabalhava no sistema carcerário. Por diversas vezes, Reed foi algemada por seus colegas. Também teve sua cabeça forçada no colo de um deles. Foi objeto de piadas com conteúdo sexual 
e, por fim, teve um aparelho de choque elétrico forçado entre as suas pernas.

A corte que julgou o caso considerou que Reed se divertia com esses incidentes porque mantinha uma relação de cordialidade com seus colegas. Outros motivos para essa conclusão da corte foram vistos no fato de que a demandante apresentava um comportamento exibicionista ao não usar sutiã, e, sobretudo, porque outras colegas mulheres tiveram êxito em deter esse tipo de comportamento anteriormente. Desde a perspectiva de Reed, porém, ela tinha que participar de tudo isso para ser aceita no grupo. Ademais, ela temia as consequências de criar confronto, já que, no ambiente policial, "arranjar briga" pode significar um grande risco à própria integridade física.

Como observam Fitzgerald, Swan e Fischer, por trás dessas leituras feitas pelos tribunais se encontra a concepção idealizada de uma "vítima de verdade", a qual se rebela contra as injustiças que sofre, fazendo denúncias tanto na esfera pública quanto na vida privada ${ }^{41}$.

Cabe, contudo, buscar compreender as verdadeiras limitações das vítimas "de carne e osso". Inclusive, tomando por parâmetro o fato de que, no geral, as pessoas supõem ter uma capacidade muito superior àquela que realmente possuem para se afastarem de atitudes com as quais não concordam. Um experimento nesse sentido demonstrou que apenas 1 das 78 jovens que participaram do estudo reagiram a comentários abusivos de cunho sexista, ao qual foram submetidas, muito embora tivessem, pouco tempo antes,

${ }^{41}$ FITZGERALD; SWAN; FISCHER, 1995, p. 131. 
atestado a certeza de uma resposta enérgica caso se deparassem com essas situações. Em verdade, o sentimento de medo que afeta as vítimas no momento do assédio costuma ser muito mais forte do que qualquer revolta ${ }^{42}$.

\section{Conclusão: a importância do gênero para a percepção do fenômeno}

Conforme busquei demonstrar, o assédio sexual constitui um fenômeno de difícil conceituação, sendo diversos os contextos em que essa expressão é utilizada. Em linhas gerais, pode-se dizer tratarse de um comportamento de natureza ou conotação sexual, indesejado ou não consentido pela pessoa a quem é dirigido.

Enquanto categoria de análise, a psicologia social considera uma tripartição do conceito de assédio sexual conforme as dinâmicas de interação envolvidas, quais sejam: (i) a atenção sexual indesejada, (ii) a coerção de natureza sexual e (iii) o assédio de gênero. Partindo dessa estrutura, diversas pesquisas medem o nível de incidência e as possíveis motivações por trás de cada um deles. Apesar de ser configurado como comportamento de conotação sexual, o assédio sexual se mostra muitas vezes não como uma ação motivada por interesses sexuais, mas sim como um instrumento para expressar hostilidade de natureza sexista contra as pessoas às quais se dirigem.

Confirmando esse raciocínio, diversos estudos apontam serem as mulheres as principais vítimas do assédio sexual, embora os homens também o sejam. No caso da vitimização masculina, porém, os

${ }^{42}$ Sobre o estudo, vide DIEHL; REES; BOHNER, 2014, p. 26. 
homens figuram em grande medida como os próprios agressores. Isso aponta para o fato de que se trata de um fenômeno eminentemente relacionado às características da socialização masculina.

Tomando por parâmetro o estágio da pesquisa empírica na atualidade, pode-se mesmo dizer que não existem dúvidas quanto ao papel essencial desempenhado pela socialização dos gêneros para a percepção do assédio sexual, isto é, sobre a assimilação, através da convivência, dos padrões e expectativas a serem cumpridos no que se refere ao papel da mulher e ao papel do homem. Apesar disso, existe certa divergência acerca da importância da biologia nas razões que explicam o assédio sexual.

De todo modo, o gênero é uma categoria fundamental a ser considerada para a interpretação e a compreensão do assédio sexual. Experiências comportamentais similares podem ter significados bastante diversos para homens e mulheres. Isso porque existe entre os gêneros uma grande assimetria no que se refere à superioridade de poder dos homens em relação às mulheres, seja no âmbito social, no campo institucional, e até mesmo físico.

Desta forma, um julgamento adequado sobre as possíveis reações das vítimas do assédio sexual depende da capacidade de compreender as limitações do que significa ser mulher e ser homem num dado tempo e espaço. Sobretudo o espaço institucional oferece restrições à liberdade de ação das pessoas assediadas, não devendo essa realidade ser desconsiderada ou interpretada em desfavor dessas pessoas. Ainda assim, cabe ponderar que muitas leituras são determinadas por mitos vigentes no ambiente cultural em que nos encontramos. Os mitos sobre o assédio sexual persistem, apesar do esclarecimento trazido pelas pesquisas empíricas e das vozes de 
especialistas que buscam oferecer uma análise mais complexa dos fatores envolvidos no assédio sexual. São pontos de fuga ainda necessários a muitos de nós, fragilizados perante o confronto com a própria condição humana.

\section{REFERÊNCIAS}

BAKER, Carrie N. The Women's movement against sexual harassment. Cambrigde: Cambrigde University Press, 2008.

BOHNER, Gerd; EYSSEL, Friederike; PINA, Afroditi; SIEBLER, Frank; VIKI, G. Tendayi. Rape myth acceptance: cognitive, affective and behavioural effects of beliefs that blame the victim and exonerate the perpetrator. In: BROWN, Jennifer; HORVATH, Miranda. Rape: Challenging contemporary thinking. Cullompton: Willan, 2009.

CAMARGO, Beatriz Correa; FERREGUTTI, B. Cifras ocultas do crime de assédio sexual: conscientização e atenção assistencial à vítima nas universidades brasileiras. In: SAAD-DINIZ, Eduardo. O lugar da vítima nas ciências criminais. 1 ed. São Paulo: Liber Ars, 2016.

CAMARGO, Beatriz Correa; SILVEIRA, Renato de Mello Jorge. O crime de importunação sexual: resposta adequada ao assédio sexual de rua? Boletim do IBCCRIM, v. 26, 2018. 
CAMARGO, Beatriz Corrêa. Die Strafbarkeit der sexuellen Belästigung durch körperliche Berührung. Zeitschrift für die gesamte Strafrechtswissenschaft, 2019 (no prelo).

CAMARGO, Beatriz Correâ. O assédio sexual na reforma dos crimes sexuais na Alemanha: repensando a escolha brasileira. Boletim do IBCCRIM, v. 291, 2017.

CARDEAL, Camila Costa; RIBEIRO, Ludmila Mendonça Lopes. Relaçooes de gênero nas Guardas Municipais. Revista brasileira de segurança pública, v. 11, Fev/Mar 2017.

DATA POPULAR; INSTITUTO AVON. Violencia contra a mulher no ambiente universitário. Pesquisa realizada com alunas e alunos dos cursos de graduação e pós- graduação de universidades brasileiras. São Paulo, 2015. Disponível em: <http://www.onumulheres.org.br/wpcontent/uploads/2016/04/Pesquisa-InstitutoAvon_V9_FINAL_Bx.pdf >. Acesso em: 3 fev. 2019.

DATAFOLHA. Assédio sexual entre as mulheres - PO 813942 (29 e 30/11/2017).

Disponível em: http:/datafolha.folha.uol.com.br/opiniaopublica/2018/01/194970142-das-mulheres-ja-sofreram-assedio-sexual.shtml. Acesso em: $07 \mathrm{fev}$. 2019.

DIEHL, Charlotte; GLASER, Tina; BOHNER, Gerd. Face the Consequences: Learning About Victim's Suffering Reduces Sexual 
Harassment Myth Acceptance and Men's Likelihood to Sexually Harass. Aggressive Behavior, vol. 40, 2014.

DIEHL, Charlotte; REES, Jonas; BOHNER, Gerd. Die SexismusDebatte im Spiegel wissenschaftlicher Erkenntnisse. Aus Politik und Zeitgeschichte, vol. 64, 2014.

DIEHL, Charlotte; REES, Jonas; BOHNER, Gerd. Flirting with disaster: short-term mating orientation and hostile sexism predict different types of sexual harassment. Aggressive Behavior, vol. 38, 2012.

EUROPEAN COMMISSION. Sexual Harassment in the Workplace in the European Union, 1998, p. 133. Disponível em: www. un.org/womenwatch/osagi/pdf/shworkpl.pdf. Acesso em: $08 \mathrm{fev}$. 2019.

FITZGERALD, Louise; SWAN, Suzanne; FISCHER, Karla. Why Didn't She Just Report Him? The Psychological and Legal Implications of Women's Responses to Sexual Harassment. Journal of Social Issues, vol. 51, 1995.

GELFAND, Michele J., FITZGERALD, Louise F., DRASGOW, Fritz. The structure of sexual harassment: A confirmatory analysis across cultures and settings. Vocational Behavior 47, 1995.

HOLZBECHER, Monika; BRASZEIT, Anne; MÜLLER, Ursula; PLOGSTEDT, Sibylle. Sexuelle Belästigung am Arbeitsplatz. Köln: Kohlhammer, 1997. 
KINDHÄUSER, Urs. Die deutsche Strafrechtsdogmatik zwischen Anpassung und Selbstbehauptung - Grenzkontrolle der Kriminalpolitik durch die Dogmatik. Zeitschrift für die gesamte Strafrechtswissenschaft, vol. 121, 2009.

MACKINNON, Catharine A. Only Words. Cambridge: Harvard University Press, 1993.

MACKINNON, Catharine A. Sexual Harassment of Working Women: A Case of Sex Discrimination. Yale: Yale University Press, 1979.

MORRAL, Andrew R. et al. Sexual Assault and Sexual Harassment in the U.S. Military. Volume 2. Estimates for Department of Defense Service Members from the 2014 RAND Military Workplace Study. Santa Monica: RAND Corporation, 2015

RUSSELL, Brenda L.; OSWALD, Debra. When Sexism Cuts Both Ways: Predictors of Tolerance of Sexual Harassment of Men. Men and Masculinities, vol. 19, 2016.

SAGUY, Abigail Cope.s-p. What is sexual harassment? from Capitol Hill to the Sorbonne. Berkeley: University of California Press, 2003.

SIEGEL, Reva B. A Short History of Sexual Harassment. In: MacKinnon, Catharine A. and Reva B. Siegel, (Org.). Directions in Sexual Harassment Law. New Haven: Yale University Press, 2004.

SIGUSCH, Volkmar. Auf der Suche nach der sexuellen Freiheit - über Sexualforschung und Politik. Frankfurt: Campus, 2011. 
US MERIT SYSTEMS PROTECTION BOARD. Sexual Harassment in the Federal Government: Trends, Progress, Continuing Challenges. Washington, DC: US Merit Systems Protection Board, 1995.

VANSELOW, Nina. Of Beauties, Beaus, and Beasts: Studying Women's and Men's Actual and Imagined Experiences of Sexual and Gender Harassment. Tese de doutorado. Universidade de Bielefeld, Faculdade de Psicologia. Bielefeld, 2009.

VERA-GRAY, F. Men's stranger intrusions: Rethinking street harassment. Women's Studies International Forum, vol. 58, 2016.

WALDO, Craig R.; BERDAHL, Jennifer L.; FITZGERALD, Louise F. Are men sexually harassed? If so, by whom? Law and Human Behavior, vol. 22, 1998.

WITTGENSTEIN, Ludwig. Philosophische Untersuchungen. Frankfurt am Main: Suhrkamp, 2006.

WREDE, Birgitta. Was ist Sexualität? In: SCHMERL, Christiane et al. (org.), Sexuelle Szenen: Inszenierungen von Geschlecht und Sexualität in modernen Gesellschaften. Opladen: Leske und Budrich, 2000. 